\title{
EL COMBATE A LA CORRUPCIÓN EN MÉXICO'1
}

JORGE FERNÁNDEZ RUIZ²

SUMARIO: I Introducción. II. Planteamiento del problema. III. Nichos de corrupción y propuestas de solución

\section{REsumen}

El documento se refiere al fenómeno de la corrupción que se da tanto en el ámbito público como privado, nacional e internacional. La corrupción corroe las entrañas del México de nuestros días, circunstancia que impide el sano desarrollo del país y amenaza su existencia misma. Consiguientemente, habrán de considerarse a la corrupción y a la impunidad como una grave amenaza latente para todo el sector público y para la sociedad entera; en consecuencia, no debe escatimarse esfuerzo alguno ni medida necesaria para prevenirla, combatirla y reprimirla. Los temas torales de la problemática nacional contemporánea son la seguridad pública, el avance incontenible de la pobreza, la inseguridad cuya presencia se advierte lo mismo en el campo que en la ciudad; en la vía pública, en el interior de los bancos y demás establecimientos mercantiles, en el transporte público y privado, en los centros de

${ }^{1}$ Conferencia Magistral presentada en la Universidad de Sonora en el marco de la I Jornada de la Celebración del Día Internacional del Combate a la corrupción, el 0912-19 en el Auditorio de la División de Ciencias Económicas y Administrativas "Astolfo Chavarín"

2 Abogado, Licenciado en Economía, Maestro en Administración Pública, Doctor en Derecho. Profesor Nivel PRIDE D, de la UNAM y otras 21 Universidades de México y del extranjero, Coordinador del Área de Derecho Administrativo, Investigador Titular C del Instituto de Investigaciones Jurídicas de la UNAM e integrante del Sistema Nacional de Investigadores Nivel III, autor y/o coautor de mas de un centenar de libros,capítulos de libro, artículos inexados, videoconferencias, en materia de Derecho Administrativo,Constitucional,finanzas públicas, administración pública, así en el orden internacional,nacional,local y municipal https://www.juridicas.unam.mx/investigador/perfil/jorgef/libros https://www.juridicas.unam.mx/investigador/perfil/jorgef/capitulos https://www.juridicas.unam.mx/investigador/perfil/jorgef/videos 
diversión y esparcimiento y aun en domicilios particulares que con lamentable frecuencia son víctimas de asaltos. Entre las propuestas de solución está, el que corresponde a la Universidad pública, asumir un papel protagónico en el combate a la corrupción.

PALABRAS CLAVE: Combate a la corrupción, cultura de la legalidad, protagonismo de las Universidades

\section{THE FIGHT TO CORRUPTION IN MEXICO}

\section{ABSTRACT}

The document refers to the phenomenon of corruption that occurs both in the public and private, national and international spheres. Corruption corrodes the bowels of today's México, circumstance that block the healthy development of the country and threatens its very existence. Consequently, corruption and impunity must be considered as a serious latent threat to the entire public sector and to the entire society; therefore, no effort or measure necessary to prevent, combat and repress it should be spared. The main issues of contemporary national problems are public security, the unstoppable advance of poverty, insecurity whose presence is the same in the countryside as in the city; on public roads, inside banks and other commercial establishments, in public and private transport, in entertainment and recreation centers and even in private homes that are unfortunately victims of assaults. Among the proposed solutions it is found that corresponds to the public University, assume a leading role in the fight against corruption.

KEY WORDS: fight against corruption, culture of legality, leading role of universities

\section{INTRODUCCIÓN}

En coincidencia con el HOMENAJE-POST MORTEM que los integrantes de las Academias de Derecho Administrativo y de Derecho Fiscal del Departamento de Derecho de la DCS URC de la Universidad de Sonora rinden a al gran jurisconsulto e insigne catedrático de Derecho Administrativo y Derecho Fiscal de mas de un centenar de generaciones D Emilio Margain Manautou la intervención de otro gran jurista y experto generador de muchas generaciones de abogados administrativistas, 
el Doctor Jorge Fernández Ruiz nos comparte en esta ocasión su Conferencia Magistral presentada en la I Jornada de la Celebración del Día Internacional del Combate a la corrupción denominada, El combate a la corrupción en México.

\section{INTRODUCCIÓN}

El fenómeno de la corrupción constituye un ataque permanente contra la moral social e individual, contra el desarrollo económico, contra la seguridad pública y la seguridad nacional y, en última instancia, contra la familia, la sociedad y el Estado.

Obviamente la corrupción no es exclusiva del ámbito público, también se da en instituciones privadas del tipo de las fundaciones e instituciones de beneficencia que remuneran a sus dirigentes con sueldos y prestaciones estratosféricas, o que ocultan sus actividades de lucro con un disfraz filantrópico, perversión que se da también entre las empresas privadas.

En consecuencia podemos hablar de corrupción privada y corrupción pública, la que puede presentarse en dos ámbitos diferentes: el internacional y nacional; el primero concierne a los organismos internacionales, como el Banco Mundial y el Fondo Monetario Internacional, ambos sacudidos por escándalos de corrupción, que en el caso del Banco Mundial dio lugar a la renuncia de su presidente Paul Wolfowitz, y en el Fondo Monetario Internacional, los escándalos salpicaron a sus tres últimos directores: Rodrigo Rato, Dominique Strauss Khan y Cristina Lagarde.

Entendida como el deliberado desorden en el ejercicio de las funciones públicas, con miras a la obtención de un beneficio ilícito de quienes las tienen a su cargo, la corrupción gubernamental es uno de los graves males endémicos que amenaza de manera permanente el correcto desempeño de todo poder público.

El Banco Mundial la define como "el abuso del poder público para el beneficio privado", en tanto que la Unión Europea la interpreta como toda transacción hecha entre actores públicos y privados mediante la cual los recursos públicos son ilegalmente transformados en ganancias particulares.

Sin duda la corrupción se potencia cuando se une a la impunidad, porque juntas 
integran un binomio temible y poderoso, dada la falta de castigo para los autores de esos atracos al erario público, por lo cual se requiere combatirles a fondo; para ello conviene llevar a cabo una investigación que analice las causas que propician este execrable fenómeno que socaba no solo la institucionalidad política sino de toda la sociedad, a efecto de determinar las medidas sociales y políticas que conduzcan a la adecuada regulación jurídica de las actividades gubernamentales, a la que se agregue la estricta observancia de la normativa correspondiente, de ahí la trascendencia de su investigación y la importancia de la misma dentro del derecho público y de la sociología jurídica.

La corrupción en México tiene profundas y añejas raíces, ya que sus antecedentes se remontan a los tiempos de la Conquista, pues Hernán Cortés y Nuño Beltrán de Guzmán, por citar dos casos emblemáticos, hicieron uso de mecanismos que permitieron confundir los intereses de la Corona con sus personales intereses, para tratar de quedarse con la mayor parte posible del botín, lo cual dio lugar a la instauración en la Nueva España del procedimiento judicial denominado juicio de residencia.

En el México independiente la corrupción se instala desde el gobierno de Iturbide, y con el paso de los años florece resplandeciente, merced al contubernio de altos funcionarios del gobierno con los capos del crimen organizado y la cúpula empresarial, incluido el duopolio televisivo.

\section{PLANTEAMIENTO DEL PROBLEMA}

El planteamiento del problema es sencillo, por lo obvio: la corrupción corroe las entrañas del México de nuestros días, circunstancia que impide el sano desarrollo del país y amenaza su existencia misma. 
Consiguientemente, habrán de considerarse a la corrupción y a la impunidad como lo que en rigor son: una grave amenaza latente para todo el sector público y para la sociedad entera; en consecuencia, no debe escatimarse esfuerzo alguno ni medida necesaria para prevenirla, combatirla y reprimirla, so pena de naufragar en el proceloso mar de la inmoralidad, el cinismo y la ignominia.

\section{NICHOS DE CORUPCIÓN Y PROPUESTAS DE SOLUCIÓN}

El combate a la corrupción requiere del diseño e implantación de un régimen jurídico que norme adecuada y efectivamente la actuación de los servidores públicos mediante ordenamientos jurídicos adecuados.

1. La corrupción en la preservación de la seguridad pública

Tanto las encuestas como los medios de comunicación masiva indican que uno de los temas torales de la problemática nacional contemporánea es el de la seguridad pública, problema potenciado cotidianamente por el avance incontenible de la pobreza, porque con ella cabalga, en ocasiones de manera galopante, la inseguridad cuya presencia se advierte lo mismo en el campo que en la ciudad; en la vía pública, en el interior de los bancos y demás establecimientos mercantiles, en el transporte público y privado, en los centros de diversión y esparcimiento y aun en domicilios particulares que con lamentable frecuencia son víctimas de asaltos.

Uno de los ámbitos tradicionales de la corrupción en México es el de los cuerpos policiales a cuyo cargo está la preservación de la seguridad pública en la vía y lugares públicos, corrupción que presenta múltiples formas, tales como el soborno coloquialmente llamado mordida para evitar arresto o multa por infracción al Reglamento de Policía, el atraco a los trabajadores en los días de pago de quincena, la imposición de cuotas a los patrulleros o los agentes que pretenden adscripción a zonas o territorios específicos, el pago cotidiano, o semanal o quincenal, por ascensos en el escalafón; en fin, el alquiler de patrullas y uniformes a delincuentes, entre otros muchos.

2. La corrupción en el control del tránsito peatonal y vehicular 
Otro nicho de corrupción en lo concerniente a la seguridad pública es el de las corporaciones a las que se encomienda la vigilancia y regulación del tránsito peatonal y vehicular en la vía pública, a cuyos agentes, en muchas regiones del país, el vulgo les llama mordelones, en lugar de agentes de tránsito.

En cuanto a la corrupción de las corporaciones policiales de tránsito, podemos percatarnos de que surgió simultáneamente con la aparición de los automóviles, a través de la novela intitulada Gobierno que su autor suscribió como Bruno Traven, obra en la que el autor se refiere a lo codiciado que era el cargo de agente de tránsito en Tapachula, la población chiapaneca que a la sazón no tenía ni diez mil habitantes y ni siquiera cien vehículos automotores.

Evidentemente la codicia por el cargo de agente de tránsito no la despertaba el miserable sueldo que se cubría, por cierto, con retraso, sino por el importe de las mordidas cotidianas cuyo importe compartían con el superior jerárquico.

3. La corrupción en el ámbito de la protección civil

Otra área de seguridad pública que incuba frecuente corrupción es la de protección civil encargada de la prevención de desastres y siniestros, cuya labor incluye la de avisos de alarma en casos graves de emergencia, así como las de evacuación, dispersión, albergue, socorro, rescate y salvamento, en casos de hecatombes, desastres y siniestros, casos estos últimos que generan donativos en numerario y en especie que son de difícil control y, por tanto, fácilmente desviables a las arcas de funcionarios públicos corruptos.

4. La corrupción en la persecución de los autores de delitos

Deplorable resulta la frecuencia con que los medios masivos de comunicación dan cuenta de que las policías ministeriales o de investigación no detienen a los presuntos delincuentes, a pesar de tenerlos perfectamente localizados, por los sobornos que reciben y que en algunos casos llegan al extremo de prestar protección a tales criminales, en lugar de detenerlos.

5. La corrupción en la procuración de justicia 
Otra área de oportunidad en materia de corrupción la representa la de procuración de justicia que da lugar al indebido no ejercicio de la acción penal, e incluso al indebido ejercicio de la misma, o a una deliberada defectuosa actuación acusatoria del agente del ministerio público que redundará en la libertad del indiciado.

6. La corrupción en el ámbito de la impartición de justicia

Caso similar se presenta en la impartición de justicia, por repetirse muchas veces los casos en que los jueces indebidamente absuelven a delincuentes, o deliberadamente condenan infundadamente con el propósito de que esas fallas sean revocadas al resolverse su impugnación.

\section{La corrupción en la conducción de procesos electorales}

Se dice, y no sin razón, que la corrupción electoral es la madre de las demás modalidades de corrupción pública, mas independientemente de ello, en México se observa una terca proclividad a trastocar o distorsionar los resultados electorales mediante acciones ilícitas vulgarmente conocidas como mapachería electoral, encaminadas a vulnerar el carácter universal, libre, igual y secreto del voto, mediante el engaño, la manipulación, el despojo, el entorpecimiento, la violencia, e incluso la compra del voto.

8. Corrupción en materia de contratos administrativos

Entre las modalidades más rentables de la corrupción figura la ilegal adjudicación de contratos administrativos, así como el defectuoso cumplimiento de éstos. Numerosas fortunas se han originado en el contubernio de proveedores y contratistas de la administración pública con los funcionarios a cuyo cargo estuvo la contratación respectiva.

\section{La cultura de la legalidad}

Un antídoto importante contra la corrupción es promover el desarrollo de la cultura de la legalidad, inculcando en los niños, jóvenes y adultos los valores de la honradez, la probidad y la legalidad, labor que debe apoyarse en la docencia a través 


\section{El combate a la corrupción en México}

de los planes y programas de estudio en las escuelas de educación primaria, educación media y educación superior.

10. Papel de la Universidad pública en el combate a la corrupción

Además, corresponde a la Universidad pública asumir un papel protagónico en el combate a la corrupción, como ahora lo hace la Universidad de Sonora a través de este foro para analizar desde la atalaya académica este cáncer social, y sería conveniente promover con los Poderes Legislativo y Ejecutivo, celebración de convenios para la formulación de proyectos de ley, y/o de reformas, sobre este tema, a efecto de contar con un marco jurídico idóneo, elaborado por los profesores e investigadores de esta Universidad.

Muchas gracias. 